\title{
Wave of corruption: corruption laws and water access
}

\author{
A. R. Harrington \\ Albany Law School of Union University, USA
}

\begin{abstract}
Water is essential for human life and functioning. At the international and domestic level, it is well known that water is not accessible to all. There are many societal, structural and legal reasons for this lack of access, to say nothing of the lack of access to clean water rather than simply water itself.

This paper will shift the focus of water-based discussions to examine the relationship between access to water and legal regimes regarding corruption. Using international, regional and domestic corruption and water laws, this paper will analyze which regimes are applicable to corruption involving water access and how applicable regimes might be used to prevent corruption involving water access. From this analysis will come suggestions as to ways that existing corruption and other legal regimes could be strengthened to provide for more specific penalties involving corruption and water resources.
\end{abstract}

Keywords: water law, water resources, water access, corruption.

\section{Introduction}

Although water is universally recognized as an essential element of human life and societal functioning, this does not mean that water itself is universal in its form. At times water exists as a small droplet of rain, while at other times it exists as a massive wave. Similarly, corruption can take many shapes. In some instances, corruption may be small-scale, while in other instances corruption can be large-scale.

The relationship between water access and corruption is far more than metaphoric. Rather, there is a direct interrelationship between the two that threatens to restrict the former while increasing the influence of the latter. For the purposes of this paper, corruption is broadly defined using the Transparency 
International ("TI") [1] definition: "the misuse of entrusted power for private gain." The interrelationship between water access and corruption has been determined to undermine attempts at development within nearly all societies, affecting everything from food access and agriculture to poverty reduction plans to education access. This interrelationship is not, however, easily recognized in practice, particularly in the field of law. In recent years, legal actors and those from other disciplines have successfully partnered to craft international, regional and domestic law regimes to combat corruption and associated practices, protect the environment, and even to protect water safety. Despite these advances, and the well-established interrelationship between corruption and water access issues, laws that specifically acknowledge and address this interrelationship are lacking across the spectrum of international, regional and domestic jurisdictions.

This paper examines existing international, regional and domestic legal regimes that address elements of corruption and/or water access to determine their ability to specifically address the problem of corruption in regards to water access. Following this examination, the paper then makes suggestions as to potential legal regimes that could be crafted at the international, regional and domestic level so as to criminalize corruption that targets water access.

\section{Water access and corruption}

By its very unique and necessary nature, water has become a popular target for corruption at all levels. Corruption in water access varies in extent, actors involved, and projects impacted and yet all forms of corruption in the field of water access share the same elements of damage to individuals and societies.

Perhaps most fundamentally, water access is essential for human life and human health. According to TI [2], scientists estimate that globally well over one billion people suffer from uncertain access to water for even the most basic of personal and household uses. This results in threats to health and also undermines the ability of communities to develop. Insufficient access to water can also serve as a trigger for internal and international conflicts, and projections estimate that there will be increased water scarcity in certain areas of the world in the future, indicating that the ability of water access to serve as a conflict trigger is not likely to diminish. Beyond access to water for personal and household sustenance lies the issue of water access for the purposes of agricultural irrigation, which is vital for the individual farmer and the society for which he produces.

Further, access to water can be undermined through corruption in the water management contracting process (e.g. TI [2]). This is a problem in developed, developing, and least developed countries. In these situations, the actors engaging in corrupt acts are typically either state actors or quasi-state actors. Indeed, the Water Integrity Network [3] has established that privatizing or semiprivatizing water-related industries does not guarantee a delinking between water and corruption. This is also true where water-related industries are decentralized from national government control to local government control. In addition to basic access to water there is also the issue of access to safe water. This issue is 
arguably more vulnerable to manmade impediments, particularly water pollution, diversion of water resources through the construction of dams, and water drilling projects.

Corruption is fundamentally linked to water pollution in many instances. Improper inspections of industrial facilities by government inspectors, failure to prosecute those responsible for water pollution (e.g. TI [2]), failure to conduct meaningful inquiries into the industrial permitting processes or meaningful environmental impact assessments (e.g. TI [2]) are all examples. Generally, at the domestic level, groups such as TI have highlighted positive experiences with licenses as a way to combat corruption in the field of water access. However, there is an inherent danger of corruption in the licensing process and also in the process of license compliance oversight. Others, particularly the UNEP [4], have called for the "greening of water law," meaning to incorporate environmental protection issues into water law - this is fine as far as it goes but does not imply that corruption laws will be incorporated into this system as well.

As demonstrated above, water access and corruption are strongly interrelated. This interrelationship impacts on many disciplines, from environmental studies to sustainable development to public health to law. Individuals are harmed by corruption in water access and so is the larger society. More than this, business from small farmers to large corporate entities that are shut out of success in bidding for water contracts due to corruption, suffer. From a legal perspective, laws that protect the environment and promote good governance are irreparably damaged as a result of this interrelationship. Corruption and water access thus threaten to undermine the advances made across disciplines and to thwart the development of communities on the local, regional and global scale.

\section{Legal regimes}

\subsection{International regimes}

The United Nations Convention Against Corruption ("UNCAC") [5] was created as an outgrowth of the United Nations Convention against Transnational Organized Crime. It recognizes that corruption is generally corrosive to society at all levels and all aspects, including the promotion of sustainable development and the rule of law, however it does not specifically incorporate concerns about water access. Underlying the UNCAC is the realization that corruption is not a domestic issue, but rather has become truly international in application and scope, and also that combatting corruption at all levels requires an interdisciplinary approach.

The UNCAC is applicable to domestic and foreign public officials and those private actors who would seek to bribe them. The UNCAC is not an instrument that creates international criminal law - rather, it creates both suggested and required measures that those countries that have ratified its terms (commonly referred to as "State Parties") take in order to be in conformity with its terms. Under the UNCAC, State Parties are encouraged to create corruption oversight bodies, to create methods of vetting potential state employees and officials and 
watching over their potential conflicts, and to create codes of conduct for public officials. In terms of criminal sanctions, the UNCAC criminalizes a host of offences related to bribery and corruption. It established that corporations, as well as individuals, can be found liable for any of these criminal acts. These crimes are all written in a way that is not specific to corruption in any particular sector other than those involving public actors at some level and, also, these crimes do not necessarily trickle down from the national level to the local level where much corruption occurs.

Since the UNCAC is an international instrument - and individual states are required to adopt the terms of any international instrument into national law before they become binding - State Parties have adopted the criminal terms of the UNCAC at different rates and with different levels of success.

In 1997, the Organization for Economic Co-Operation and Development ("OECD") promulgated the Convention on Combatting Bribery of Foreign Public Officials in International Business Transactions ("the OECD Convention") [6]. Within this limited context, the OECD Convention recognizes that corruption undermines society, including good governance and economic development. The OECD Convention requires its State Parties to establish the crime of bribery of foreign public officials, acknowledging that inducement to corrupt acts can come from abroad as well as from home. As with the UNCAC, the OECD Convention provides that corporations will also be liable for crimes.

In terms of water law, there are many international and cross-border agreements governing the use and access of water bodies and water resources; however, these agreements do not include corruption-related issues within their terms [7]. Further, there are agreements at the international level regarding the use of Environmental Impact Assessments. These EIAs have an effect on and take into consideration water and the role of proposed projects on water-related considerations as well as environmental considerations per se. These international agreements, like their domestic counterparts, do not require that corruption be a consideration in the EIA process.

Further, there are many international instruments that address the importance of water to domestic and international environmental concerns. However, none of these international instruments explicitly link the environmental concern they address with the need to combat corruption in regards to water and access to it.

\subsection{Regional regimes}

\subsubsection{European Union}

In 1999, the Council of Europe promulgated the Criminal Law Convention on Corruption and the Civil Law Convention on Corruption [8]. Although these are both wide-ranging conventions and demonstrate the will of the Council of Europe to address the many forms that corruption takes, neither addresses water access. Further, neither was widely accepted within its target community.

Within the European Union ("EU"), which is the most governmentally centralized of the regional regimes discussed, there are several groups tasked with overseeing anti-corruption efforts. In terms of scope, the EU has taken measures to promote anti-corruption efforts within its Member States while also 
seeking to tackle the issue of corruption within the administrative and governmental apparatuses that comprise the EU itself. Corruption as a whole has been identified by the EU as a threat to its internal security and to its Member States [9]. However, the EU's statements regarding the importance of corruption as an internal security threat focus on the economic impacts of corruption and its link to organized crime rather than on the broad forms of corruption that would encompass water access, or even corruption as an environmental concern.

The EU acknowledges the essential nature of water to mankind and society and that water resources within the EU have become and will continue to be stressed [10]. The EU is proactive in terms of environmental regulation and protection, legislating in a wide swathe of areas from biodiversity to waste transportation. Overall, the EU has recognized the link between water access and environmental concerns and promotes policies that seek to protect water and environmental resources. However, the link between water access and corruption has not been legislated or regulated.

\subsubsection{Organization of American States}

The Organization of American States ("OAS") is comprised of 35 Member States from North America, Central America, Latin America and the Caribbean. OAS Member States represent a variety of development statuses and standing in terms of environmental needs and governmental susceptibility to corruption. The OAS has ratified the Inter-American Convention Against Corruption ("IACAC") [11] and has been proactive in assisting State Parties in implementing its provisions. However, the OAS does not have any specific instruments concerning water access, leaving these issues to the OAS Member States to address. The IACAC does recognize the link between corruption and a threat to "the comprehensive development of peoples," however this is the extent of environmental concerns voiced in the IACAC.

\subsubsection{Association of Southeast Asian Nations}

The prevention of corruption and the promotion of good governance and the rule of law are essential elements of ASEAN's current policies, particularly the ASEAN Political-Security Community Blueprint [12]. ASEAN Member States have committed themselves to enacting or strengthening competition laws, which is an important element in the ability of a governmental contracting system to engage in conflict of interest prevention. Such conflicts in the contracting process are important in water access, especially where water resources are delegated to either a quasi-governmental or private entity. Largely, however, the focus of the current ASEAN corruption policies is on intergovernmental cooperation and assistance rather than on specific policy areas in which corruption is highly problematic.

Some of ASEAN's earliest agreements address the importance of access to water, particularly clean water, for environmental conservation purposes [13]. An essential tenet of ASEAN's current strategic plan [14] is "the attainment of sustainability of water resources to ensure sufficient water quantity of acceptable quality to meet the needs of the people of Southeast Asia in terms of health, food security, economy and environment." In order to achieve this goal, ASEAN 
asserts that ensuring water access is essential. Interestingly, although this plan identifies many threats to water access, including environmental factors, contamination, and conflicts, it does not directly address the threats to water access posed by corruption. Indeed, this plan states that governance of water resources management is a key component to water access in each Member State in the future, but does not delve into the meaning of governance in this context. Later policy documents [15] state that access to clean drinking water is an underpinning of ASEAN's climate change policy.

\subsubsection{African Union}

The African Union ("AU") has a membership of 28 countries. The AU has promulgated the African Union Convention on Preventing and Combatting Corruption ("AU Corruption Convention") [16], however to date it has been relatively poorly ratified by AU Member States. A stated aim of the AU Corruption Convention is to promote the rule of law and good governance. A concern of the AU Corruption Convention is that the State Parties recognize the deleterious effects of corruption in the political, economic, social and cultural realms. The AU Corruption Convention creates both criminal provisions that State Parties are to enact as part of their formal domestic laws and voluntary steps for State Parties to take in order to combat domestic corruption. Further, the AU Corruption Convention extends to corruption solely within the private sector.

Under the terms of the African Convention on the Conservation of Nature and Natural Resources (“AU Nature Convention") [17], water is recognized as one of the natural resources that are "of vital importance to mankind." The AU Nature Convention stipulates that State Parties "undertake to adopt measures necessary to ensure conservation, utilization and development of . . . water . . . resources in accordance with scientific principles and with due regard to the best interests of the people." This protection applies to surface and groundwater supplies and focuses on scientific elements required to guarantee water access rather than efforts to ensure water access through curtailing corruption in the water sector. In a subsequent amendment to the AU Nature Convention, the same focus can be found, although a focus on environmental conservation and water supplies is also found.

\subsection{Selected domestic regimes}

Several domestic regimes in particular are worthy of discussion within the parameters of this paper since they represent countries that are at different stages of development, have different water access abilities and needs, and also have a variety of corruption systems. What emerges from a short overview of these domestic regimes is that, regardless of development situation or status in terms of water access needs and reputation in terms of corruption, domestic regimes as a whole do not tend to link these issues at law in a meaningful way. In addition to the highlighted domestic regimes, it should also be pointed out that, particularly in the Latin American context, many countries have created separate entities that implement and oversee water access and supply at various municipal 
and national levels. This is important because, as noted above, there are direct connections between the decentralization of such entities and corruption.

\subsubsection{Namibia}

In 2003, Namibia created the Anti-Corruption Commission [18]. The Commission is tasked with receiving complaints regarding corrupt activities and investigating them with the assistance of other governmental entities if necessary. The Commission is authorized to issue decisions on the merits of corruption allegations following its investigation. Namibian law contains multiple provisions regarding corruption and corrupt practices by public actors and also criminalizes corrupt practices in terms of the governmental contracting process

Under the terms of the Namibian water act [19], water access for all individuals is deemed to be essential, as is the "openness and transparency . . . [in] making available water resources information accessible to the public." The water act creates the position of Minister to oversee water resources within the country, and vests him with a host of powers and jurisdictional capacities. Namibia has adopted a licensing system for water access and also for the discharge of pollutants into the water.

\subsubsection{South Africa}

The South African corruption law [20] designates many activities that fall under the rubric of corruption in the public sphere. These offenses involve public and private interactions as well as purely public interactions. The South African corruption law applies to the governmental contracting process and tenders for contracts.

In the Water Act [21], South Africa specifically notes the importance and scarcity of its water resources and that these resources are essential to society. The South African Water Act discusses the need for a multisectoral approach to handling water access and resources, and also notes that, under the ideology governing the Water Act, municipal decentralization is an important goal. The South African Water Act contains extensive provisions relating to water pollution, but none relate to corruption or the place that corruption plays in generating or perpetuating water pollution. It also provides for an extensive licensing system for water usage that again does not seek to address corruption. Oversight of the water ministry is vested in a Minister and his staff, for whom extensive requirement provisions are established without the discussion of anticorruption measures. The same is true of the monitoring, assessment and information segments of the South African Water Act, which set out criminal penalties for violations of the Water Act without referring to corruption.

\subsubsection{United States}

Bribery and corruption are criminalized at the federal level in the United States through broad provisions that relate to acts taken by both parties in the bribery relationship [22]. Within these laws, there are some criminal provisions that are applicable depending upon the branch of government involved. Further, the US 
has established a system of criminal penalties at the federal level that are applicable to state authorities who engage in corrupt acts while in office.

In the US, there are a variety of statutory and regulatory measures that pertain to water, particularly the Clean Water Act and its associated regulatory schemes [23]. Under the terms of the Clean Water Act, there is an extensive permitting and environmental impact assessment requirement for the discharge of potentially polluting materials into waterbodies. Some of the oversight of water protection issues has been delegated to the states for enforcement, although the federal government, under the supervision of the Environmental Protection Agency, has retained a good deal of jurisdiction.

\section{Recommendations}

Based on the above, it is evident that water access and corruption, as separate policy fields, have become of increasing importance on the international, regional, and domestic levels. There are many reasons for this, from environmental stresses caused by climate change in the case of water access to an improved understanding of the unique harm that corruption can have on development. Interestingly, while the legal community at the international, regional, and domestic levels has been able to work with other disciplines to craft laws that address these issues separately, there has been no attempt to link the two issues. This is most surprising given that development entities, including the UNEP, and anti-corruption leaders, such as TI, have been quite vocal in stressing the damage that corruption does to water access. While certainly corruption is an element in many sectors of society, its invidious nature in terms of water access, and the wide-ranging impact that this form of corruption has on society at an environmental, economic, social and development level, make it necessary for the legal community, through an inter-disciplinary approach, to address it in a focused manner.

The above review of legal regimes highlighted the existing structures in which water access regulation and anti-corruption provisions function. Given that these structures already exist, there is, this paper argues, no need to reinvent the wheel in terms of crafting legal solutions to the issue of corruption in water access. Rather, it is argued below, the legal community, in tandem with other appropriate disciplines, can expand these existing frameworks in order to achieve this goal.

\subsection{International regimes}

The United Nations Convention against Transnational Organized Crime was a decisive step by the international community in combatting transnational crime. After several years, however, it became apparent that a more specialized international instrument was needed to combat corruption; the UNCAC was the end result of this realization. The UNCAC has been established as a powerful tool for anti-corruption efforts at the international legal level. In addition to the terms of the UNCAC itself, the continued monitoring of UNCAC 
implementation and conference of the parties discussions as to issues in application and methods to overcome them, make the UNCAC a strong apparatus in fighting corruption.

The relevant lesson from the UNCAC's history is that there is an established precedent for crafting additional international instruments to combat problems that become apparent over time. With this in mind, it is the argument of this paper that, in the international context, a protocol to the UNCAC that addresses the issue of corruption in water access should be created. This protocol would explicitly recognize the link between corruption and water access and would craft both voluntary provisions and criminal penalties. The criminal provisions would specifically penalize corruption in the multiple governmental facets relating to water access where corruption can occur, from the low-level municipal actor to the high-level actors who are involved in deciding national contractual issues. The voluntary provisions would stress the importance of understanding the harms caused by corruption in water access and would also encourage State Parties to engage community actors in order to determine the scope of corruption in water access that currently exists.

Protocols are standard tools in international law and have been effectively used in policy areas ranging from weapons control to human rights. A protocol is recommended over an entirely new convention because it is believed that the terms of the UNCAC itself are essential to preventing corruption in water access. Thus, a protocol that binds the State Party to the UNCAC and recognizes that there is a significant associated issue that needs to be addressed is preferable to writing an entirely new convention.

There is also room for a similar protocol to the OECD Convention, one that would target acts of bribery of foreign public officials for projects that involve or impinge upon - water access. Given the recent trend toward privatization of water resource agencies in many countries, such a protocol would be particularly prescient.

While the environmental treaties discussed above are extremely important to water access issues, they do not contain, nor are they intended to contain, the punitive measures necessary to fully address corruption in water access. Thus, although it is important that future environmental treaties and protocols, such as the yet to be adopted successor to the Kyoto Protocol, recognize that corruption in water access is an important threat to the environment generally, and to specific environmental issues such as biodiversity and desertification, it is recommended that the immediate protocol be made to the UNCAC instead.

\subsection{Regional regimes}

The regional regimes discussed in this paper represent a wide range of member state interests and also reflect different priorities given the developmental status of their member states. Regardless of member state developmental status, however, corruption in water access is an important issue to each regional regime and its members. Thus, it is recommended that each regional regime create legal instruments and policies that address corruption in water access. 
For the European Union, this is important in order to further the goals of its elaborated environmental policies and also to support its strong stance against corruption. At present, the focus of the EU's corruption policies is split between organized crime and financial crime. However, this policy should be updated to recognize that corruption is an essential policy interest, particularly in regard to water access, and that this form of corruption poses a serious threat to the EU and its Member States.

The OAS already has a robust anti-corruption convention and oversight body that not only monitors its implementation but also offers assistance to member states in implementing its terms. For the same reasons advanced in support of a protocol to the UNCAC, this paper advocates a similar protocol to the IACAC that would address the issue of corruption in water access. Since many OAS members have created water administration corporations or quasi-governmental entities to administer water services, it would be important that such a protocol specifically address bribery and corruption in these areas.

ASEAN members are in a unique position in that they are, by and large, facing the similar developmental issues. Through its instruments and policy statements, ASEAN has stressed the importance of environmental protection and preservation and the need to combat corruption in order to promote security and growth. It would be a small but vital step for ASEAN to establish a policy statement on corruption in water access and to encourage dialogue between Member States on the issue.

Through its conventions, the AU has established an appreciation for the importance of water access and the need to protect and promote water access in order to benefit society. Unfortunately, the same positive reception has not greeted the AU's Corruption Convention, although corruption is an acknowledged impediment to development among the AU Member States. While support for the AU Corruption Convention is lagging, this paper advocates its amendment to include corruption in water access because this is a pressing issue that at once needs to be addressed and also could serve as a catalyst to restart the push for ratification of the AU Corruption Convention.

\subsection{Domestic regimes}

The needs of each individual country, and the parameters of its legal system, necessarily vary and require an intensive evaluation before country-specific recommendations can be made. However, using the discussed countries Namibia, South Africa and the United States - as examples, as well as the general lessons learned from other states, it is possible to craft some overall recommendations.

From the outset, it is important that a country have strong corruption laws and equally strong means of implementing these laws. Corruption laws, as with any other form of law, have little meaning if they are only respected on paper. It is recommended that domestic corruption laws be examined and either amended to include a specific reference to corruption in the water sector or to make this form of corruption part of an already existing list of forms of corruption. 
Caution is needed with corruption reforms, however. For example, TI (TI [2]) has found that there is an inherent danger in designing corruption reforms when the overall system in which they are intended to operate is essentially lax or accepts corruption as part of allowable governance practices. It has also noted that there are dangers in involving the private sector in ending the link between corruption and water access because of the ability of private entities to become subject to corrupt influences themselves. However, the combination of a strong governmental structure that is committed to good governance and the subsequent presence of the private sector has been recommended as a way to realistically address corruption and water access.

Environmental laws that protect water resources and water access are equally important. In this vein, it is necessary for these laws to be tailored to the environmental needs and concerns of a particular country and area so that these laws are truly effective and meaningful. Licensing for the use of water resources and also for the emission of potentially polluting materials into a waterbody is a consistently used regulatory method across countries. On the surface, licensing is a good way to balance the commercial potential of water with the individual and societal access to clean water. However, throughout the standard licensing system there are many areas in which corruption can occur and it is important that this potential is addressed through anti-corruption provisions. The same is true of environmental impact assessment systems.

Corruption in water access must be addressed when a country decides to create a governmental or quasi-governmental entity that handles water resources or to offer contracts to private entities for the administration of water resources and water access. The examples above illustrate the many ways in which corruption can occur in these situations, from an employee seeking a bribe to connect a family to water pipes to a corporate actor paying a bribe to the governmental actor in charge of deciding the outcome of a contract bid. These forms of corruption, and the wide range that lies in-between, are invidious and destabilizing to the individual and the legal system as a whole. Thus, it is recommended that corruption within these forms of entities be specifically prohibited by statutory and regulatory provisions.

\section{Conclusion}

This paper began with the observation that water can take the form of a droplet or a wave. The point of the paper, and its recommendations, is to highlight the wave of corruption in water access that exists at the international and domestic level and the threats that this wave poses to all levels of society. As issues involving water and society are examined at an in-depth level, it is vital that the connection between corruption and water access be understood and combatted so that society can be strengthened through positive growth and development abilities that are stifled by corruption. The recommendations in this paper are intended as suggestions to frame debate on the issue and to suggest ways that the wave of corruption can be weakened before it crests. 


\section{References}

[1] Stålgren, P. Corruption in the Water Sector: Causes, Consequences and Potential Reform, Swedish Water House Policy Brief Nr. 4. SIWI, pp. 6, 2006.

[2] Transparency International, Global Corruption Report 2008, Cambridge University Press: Cambridge, United Kingdom, pp. xxiii, 2008.

[3] Water Integrity Network, Synthesis Report: Regional Workshops 2007 2008, Corruption and water: Experiences in Africa, Asia and Latin America, Water Integrity Network: Berlin, pp. 7, 2008.

[4] United Nations Environment Programme, The Greening of Water Law: Managing Freshwater Resources for People and the Environment, UNEP Division of Environmental Law and Conventions: New York, 2010.

[5] United Nations Convention Against Corruption, 2003.

[6] OECD, Convention on Combatting Bribery of Foreign Public Officials in International Business Transactions, 1997.

[7] United Nations Environment Programme, The Greening of Water Law: Managing Freshwater Resources for People and the Environment, UNEP Division of Environmental Law and Conventions: New York, pp. 37 - 39, 2010 .

[8] Council of Europe, Criminal Law Convention on Corruption, 1999; Council of Europe, Civil Law Convention on Corruption, 1999.

[9] European Council, The Stockholm Programme - An Open and Secure Europe Serving and Protecting Citizens, pp. 17, 2010.

[10] European Parliament and Council, Directive 2000/60/EC - establishing a framework for Community action in the field of water policy, 2000.

[11] Organization of American States, Inter-American Convention Against Corruption, 1996.

[12] ASEAN, ASEAN Political-Security Community Blueprint, 2009.

[13] ASEAN, ASEAN agreement on the conservation of nature and natural resources, 1985.

[14] ASEAN, ASEAN Strategic Plan of Action on Water Resource Management, 2005.

[15] ASEAN, Singapore Declaration on Climate Change, Energy and the Environment, 2007.

[16] African Union, African Union Convention on Preventing and Combatting Corruption, 2003.

[17] African Union, African Convention on the Conservation of Nature and Natural Resources, 1969.

[18] Republic of Namibia, Anti-Corruption Act, 2003.

[19] Republic of Namibia, Water Resources Management Act, 2004.

[20] Republic of South Africa, Prevention and Combating of Corrupt Activities Act, 2003.

[21] Republic of South Africa, National Water Act, 1998.

[22] 18 United States Code pt. 1, ch. 11, 2010.

[23] 33 United States Code ch. 26, 2010. 